\title{
CARACTERIZAÇÃO FÍSICO-QUÍMICA E SENSORIAL DE HAMBÚRGUER VEGETAL ELABORADO À BASE DE CAJU
}

\author{
Physical chemical and sensory characterization of vegetal \\ hamburger elaborated from cashew apple
}

\author{
Janice Ribeiro Lima ${ }^{1}$
}

\begin{abstract}
RESUMO
A elaboração de produtos derivados do caju é uma alternativa para seu aproveitamento e para o consumo fora o período de safra. Objetivou-se neste trabalho caracterizar hambúrgueres elaborados à base de caju e comparar suas características com as de produtos comerciais. Foram adquiridos quatro tipos de hambúrgueres comerciais, um deles à base de carne e os demais à base de proteína vegetal. Os hambúrgueres foram analisados quanto às características físico-químicas (proteína, gordura, umidade, cinzas, carboidratos, atividade de água e pH) e aceitação sensorial (aparência, aroma, sabor, textura e impressão global). Foram observadas grandes variações nas características dos hambúrgueres: proteínas variaram de 5,75 a 12,95\%, gordura de 5,79 a 16,44\%, umidade de 45,83 a $63,71 \%$, cinzas de 2,89 a $4,75 \%$, carboidratos de 16,35 a 33,99\%, atividade de água de 0,958 a 0,983 e pH de 4,75 a 6,78 . Os hambúrgueres de caju apresentaram menor $\mathrm{pH}$ e menores teores de proteína e gordura do que a maioria dos produtos comerciais. A aceitação sensorial também apresentou grandes variações, com notas para aparência de 6,2 a 7,8, aroma de 6,1 a 7,9, sabor de 5,7 a 8,0, textura de 5,9 a 7,9 e impressão global de 5,9 a 7,9. Para o hambúrguer de caju, a aceitação sensorial foi, em média, próxima da avaliação gostei ligeiramente (nota 6,0), para todos os atributos avaliados.
\end{abstract}

Termos para indexação: Anacardium occidentale L.; processamento; composição, hamburger, parâmetros físico-químicos.

\section{ABSTRACT}

Products elaborated from cashew are good alternatives for their utilization and for consumption after harvest period. This work aimed to characterize hamburgers made from cashew apple and to compare their characteristics with the ones from commercial products. Four kinds of commercial products were bought, one made of meat and the others made of vegetal protein. Hamburgers were analyzed for their physical chemical characteristics (protein, fat, moisture, ash, carbohydrates, water activity and $\mathrm{pH}$ ) and sensory acceptance (appearance, flavor, taste, texture and overall acceptance). Great variations were observed among hamburgers characteristics: proteins from 5.75 to $12.95 \%$, fat from 5.79 to $16.44 \%$, moisture from 45.83 to $63.71 \%$, ash from 2.89 to $4.75 \%$, carbohydrates from 16.35 to $33.99 \%$, water activity from 0.958 to 0.983 and $\mathrm{pH}$ from 4.75 to 6.78 . Cashew hamburgers showed less $\mathrm{pH}$, protein and fat content than the major commercial products. Great variations were also observed for sensory acceptance, being within 6.2 to 7.8 for appearance, 6.1 to 7.9 for flavor, 5.7 to 8.0 for taste, 5.9 to 7.9 for texture and 5.9 to 7.9 for overall acceptance. Average sensory notes were nearly like slightly (note 6.0) for all analyzed attributes of cashew hamburger.

Index terms: Anacardium occidentale L.; processing; composition, hamburger, physical-chemical parameters.

(Recebido em 15 de fevereiro de 2007 e aprovado em 9 de julho de 2007)

\section{INTRODUÇÃO}

A agroindústria de caju do Nordeste tem relevante importância sócio-econômica para o país, uma vez que explora 700 mil hectares de cajueiros, mobilizando, no campo, cerca de 280 mil pessoas e proporcionando uma produção de, aproximadamente, 200 mil toneladas de castanha e 2 milhões de toneladas de pedúnculo por ano, sendo $60 \%$ oriunda de pequenos produtores, que praticam a cajucultura familiar (LEITE, 1994; PAULAPESSOA et al., 1995).

O pedúnculo, além do consumo como fruta fresca, pode ser utilizado na fabricação de diferentes produtos, tais como suco, néctar, doces e compotas. Em peso, o caju é composto por $10 \%$ de castanha e $90 \%$ de pedúnculo. Dessas duas partes, o pedúnculo apresenta o menor aproveitamento (estima-se inferior a $12 \%$ da produção). $\mathrm{O}$ grande desperdício do pedúnculo é devido à reduzida estabilidade pós-colheita, associada à pequena capacidade de absorção da indústria e curto período de safra (PAIVA et al., 2000). A elaboração e consumo de produtos obtidos a partir do pedúnculo de caju proporcionam uma alternativa de aproveitamento, além da possibilidade de diversificação da dieta da população.

Siqueira et al. (2002) avaliaram a substituição parcial de carne bovina por bagaço de caju na elaboração de 
hambúrgueres. Os resultados mostraram que a adição de até $10 \%$ de bagaço não causou mudanças sensoriais significativas no produto.

Lima et al. (2002) realizaram a caracterização físicoquímica de bagaços secos de caju e de outras frutas e testaram a utilização dessas fibras em biscoitos regionais, na proporção de 5 e $8 \%$, apresentando esses aceitação sensorial média de 6,05 e 6,55, respectivamente, em escala de 9 pontos. Matias et al. (2005), também testaram a incorporação de bagaço de caju a biscoitos tipo cookie, em adições de 0, 5, 10 e 15\%, obtendo índice de aceitabilidade sensorial superior à $70 \%$. Esses resultados indicam o potencial da utilização de produtos alternativos, como fibras de caju, na formulação de produtos tradicionais.

Considerando-se que o conhecimento sobre as características de produtos obtidos a partir do pedúnculo do caju ainda é muito empírico, objetivou-se nesse trabalho caracterizar hambúrgueres elaborados à base de pedúnculos de caju e comparar essas características com as de produtos similares, elaborados à base de soja, e convencionais (à base de carne), adquiridos no mercado.

\section{MATERIAL E MÉTODOS}

Os hambúrgueres de caju foram elaborados segundo indicações de Cione (198-), Embrapa (2007) e Vortal do Caju (2007). Utilizou-se a carne básica de caju, obtida depois de liquidificar o fruto, peneirá-lo até adquirir uma fibra enxuta e refogá-lo junto com outros ingredientes (cebola, pimentão, alho, tomate, tempero comercial, e cheiro verde). A carne básica foi, então, misturada com farinha de trigo, sendo a massa resultante aberta sobre mesa inox, para obter uma lâmina, a partir da qual foram formados os hambúrgueres. As proporções utilizadas foram de $89 \%$ de fibra, $3 \%$ de farinha de trigo comercial e $8 \%$ dos demais insumos. Os hambúrgueres foram embalados em sacos plásticos de polietileno e congelados em freezer doméstico $\left(-18^{\circ} \mathrm{C}\right)$, até o momento das análises.

Quatro tipos de hambúrgueres, de marcas conhecidas no mercado nacional, foram adquiridos em supermercados de Fortaleza, Ceará. Dessas marcas, uma apresentava como base a carne bovina e três a proteína vegetal (Quadro 1).

Quadro 1 - Características dos hambúrgueres comerciais analisados.

\begin{tabular}{|c|c|c|c|c|}
\hline Código & $\bar{A}$ & $\mathrm{~B}$ & $\mathrm{C}$ & $\mathrm{D}$ \\
\hline Base & Carne Bovina & Proteína de Soja & Proteína Vegetal & $\begin{array}{l}\text { Proteína Vegetal } \\
\text { sabor frango }\end{array}$ \\
\hline $\begin{array}{l}\text { Peso por } \\
\text { embalagem }(\mathrm{g})\end{array}$ & 672 & 448 & 420 & 420 \\
\hline $\begin{array}{l}\text { Unidades por } \\
\text { embalagem }\end{array}$ & 12 & 8 & 6 & 6 \\
\hline $\begin{array}{l}\text { Preço por } \\
\text { embalagem }(\mathrm{R} \$)^{*}\end{array}$ & 6,21 & 9,89 & 10,50 & 13,10 \\
\hline $\begin{array}{l}\text { Preço por quilo } \\
(\mathrm{R} \$)^{*}\end{array}$ & 9,24 & 22,07 & 25,00 & 31,19 \\
\hline Validade (meses) & 4 & 6 & 4 & 6 \\
\hline $\begin{array}{l}\text { Ingredientes } \\
\text { declarados na } \\
\text { embalagem }\end{array}$ & $\begin{array}{l}\text { Carne bovina, } \\
\text { gordura bovina, } \\
\text { água, proteína } \\
\text { vegetal, sal, } \\
\text { especiarias, } \\
\text { realçador de sabor } \\
\text { glutamato } \\
\text { monossódico, } \\
\text { antioxidante } \\
\text { eritorbato de sódio. }\end{array}$ & $\begin{array}{l}\text { Proteína } \\
\text { texturizada de soja, } \\
\text { água, óleo de } \\
\text { milho, fibra } \\
\text { alimentar, } \\
\text { condimentos } \\
\text { naturais, sal } \\
\text { hipossódico, } \\
\text { proteína } \\
\text { hidrolisada } \\
\text { vegetal, corante } \\
\text { natural, } \\
\text { aromatizante } \\
\text { aroma natural. }\end{array}$ & $\begin{array}{l}\text { Água, proteína concentrada } \\
\text { texturizada de soja, gordura } \\
\text { vegetal hidrogenada, óleo de } \\
\text { soja, proteína isolada de soja, } \\
\text { glúten de trigo, clara de ovo em } \\
\text { pó, leite em pó, condimentos } \\
\text { naturais, sal, maltodextrina, } \\
\text { proteína vegetal hidrolisada, } \\
\text { pimenta preta, estabilizante } \\
\text { metilcelulose, realçador de sabor } \\
\text { glutamato monossódico, aroma } \\
\text { natural e corante caramelo III. }\end{array}$ & $\begin{array}{l}\text { Proteína } \\
\text { texturizada de } \\
\text { soja, glúten de } \\
\text { trigo, gordura } \\
\text { vegetal } \\
\text { hidrogenada, alho, } \\
\text { cebola, sal e } \\
\text { condimentos } \\
\text { naturais. }\end{array}$ \\
\hline
\end{tabular}

*(abril/2006) 
Os hambúrgueres foram retirados do freezer e imediatamente preparados, como para consumo doméstico, em grelha antiaderente elétrica, sem adição de óleo, a $170^{\circ} \mathrm{C}$ por 14 minutos, virando-se a cada 2 minutos.

Para as análises físico-químicas utilizaram-se 3 unidades de hambúrgueres, de peso variando entre 56 e $70 \mathrm{~g}$, que foram triturados e homogeneizados para obtenção de uma amostra composta, que foi então analisada em triplicata. Realizaram-se, análises físico-químicas de $\mathrm{pH}$, umidade, cinzas e gordura (INSTITUTO ADOLFO LUTZ, 1985); proteína por micro Kjeldahl (CECCHI, 1999) e atividade de água instrumental (aparelho Decagon CX-2). Carboidratos foram determinados por diferença dos demais constituintes.

Os testes de aceitação sensorial por atributos foram realizados por 50 provadores não treinados, em cabines individuais, utilizando-se escala hedônica estruturada de 9 pontos, variando de desgostei muitíssimo (nota 1) a gostei muitíssimo (nota 9) (MEILGAARD et al., 1987). As amostras foram entregues isoladamente aos provadores, à temperatura aproximada de $60^{\circ} \mathrm{C}$, na quantidade aproximada de $35 \mathrm{~g}$, equivalente a meio hambúrguer, em pratos plásticos brancos, codificados com números de três dígitos, acompanhadas de um copo de água para ser utilizado pelo provador entre as amostras. Utilizou-se luz branca para iluminação das cabines. As amostras foram avaliadas pelos mesmos 50 provadores em duas sessões, sendo que, na primeira, apresentaram-se três amostras e na segunda, as duas amostras restantes. A apresentação das amostras foi realizada em blocos inteiramente casualizados (5 tratamentos, 50 repetições), de acordo com Macfie et al. (1989).

Os resultados das análises físico-químicas e sensoriais foram avaliados por análise de variância e teste de média (Tukey) a 5\% de significância.

\section{RESULTADOS E DISCUSSÃO}

Os resultados das análises físico-químicas realizadas nos hambúrgueres apresentam-se na Tabela 1.

Os hambúrgueres de caju apresentaram teores de proteína e de cinzas inferiores a três dos hambúrgueres comerciais. O baixo teor de proteína já era esperado, pois frutos não são tipicamente fontes desse nutriente. Em contrapartida, o teor de gordura também foi inferior e o de carboidratos superior que a maioria dos produtos comerciais, caracterizando o produto como uma alternativa de alimentação para grupos da população que não ingerem derivados de carne ou que estão em busca de um produto menos calórico.

Considerando que hambúrgueres elaborados à base de caju não são produtos tradicionais, não foram encontrados dados na literatura para comparação de resultados. O baixo teor de proteína sugere que outras formulações, talvez com a adição de produtos derivados de soja, sejam uma opção quando se visar a utilização por grupos com deficiência desse nutriente.

Foram observadas diferenças significativas na atividade de água das amostras analisadas, sendo que todos os valores foram superiores a 0,958. Esses valores são bastante altos, no entanto, como os hambúrgueres são armazenados congelados e preparados apenas no momento de consumo, não existe problema para sua conservação. Os valores de umidade também foram altos, variando de 45,83 a $63,71 \%$, o que reforça a necessidade de conservação sob congelamento.

$\mathrm{O} \mathrm{pH}$ dos hambúrgueres de caju foi significativamente inferior ao dos hambúrgueres comerciais, o que pode ter influenciado de forma negativa a aceitação sensorial do produto, já que os consumidores tendem a esperar que formulações novas de produtos sejam semelhantes aos tradicionais, já disponíveis no mercado (Tabela 2).

Tabela 1 - Parâmetros físico-químicos dos hambúrgueres.

\begin{tabular}{lccccc}
\hline \multicolumn{1}{c}{ Análises } & Caju & A & B & C & D \\
\hline Proteína (\%) & $5,75 \mathrm{~b}$ & $12,57 \mathrm{a}$ & $5,04 \mathrm{~b}$ & $12,95 \mathrm{a}$ & $12,87 \mathrm{a}$ \\
Gordura (\%) & $7,90 \mathrm{~d}$ & $10,96 \mathrm{~b}$ & $5,79 \mathrm{e}$ & $16,44 \mathrm{a}$ & $9,74 \mathrm{c}$ \\
Umidade (\%) & $49,47 \mathrm{~b}$ & $55,37 \mathrm{ab}$ & $63,71 \mathrm{a}$ & $45,83 \mathrm{~b}$ & $49,51 \mathrm{~b}$ \\
Cinzas (\%) & $2,89 \mathrm{c}$ & $4,75 \mathrm{a}$ & $3,88 \mathrm{~b}$ & $3,40 \mathrm{bc}$ & $3,51 \mathrm{~b}$ \\
Carboidratos (\%, por diferença) & $33,99 \mathrm{a}$ & $16,35 \mathrm{~b}$ & $21,58 \mathrm{ab}$ & $21,38 \mathrm{ab}$ & $24,37 \mathrm{ab}$ \\
Atividade de água & $0,961 \mathrm{~cd}$ & $0,962 \mathrm{c}$ & $0,983 \mathrm{a}$ & $0,967 \mathrm{~b}$ & $0,958 \mathrm{~d}$ \\
$\mathrm{pH}$ & $4,75 \mathrm{~b}$ & $6,61 \mathrm{a}$ & $6,61 \mathrm{a}$ & $6,78 \mathrm{a}$ & $6,60 \mathrm{a}$ \\
\hline
\end{tabular}

A - carne bovina; B, C e D - proteína vegetal. Médias seguidas de mesma letra, em cada linha, não diferem entre si ao nível de erro de $5 \%$, pelo teste de Tukey. 
LIMA, J. R.

Tabela 2 - Aceitação sensorial dos hambúrgueres (escala de 9 pontos).

\begin{tabular}{llllll}
\hline \multicolumn{1}{c}{ Atributo } & Caju & A & B & C & D \\
\hline Aparência & $6,2 \mathrm{c}$ & $7,4 \mathrm{ab}$ & $6,9 \mathrm{bc}$ & $7,8 \mathrm{a}$ & $6,6 \mathrm{bc}$ \\
Aroma & $6,1 \mathrm{~d}$ & $7,6 \mathrm{ab}$ & $6,9 \mathrm{bc}$ & $7,9 \mathrm{a}$ & $6,8 \mathrm{~cd}$ \\
Sabor & $5,7 \mathrm{c}$ & $8,0 \mathrm{a}$ & $6,8 \mathrm{~b}$ & $8,0 \mathrm{a}$ & $6,5 \mathrm{bc}$ \\
Textura & $6,3 \mathrm{~cd}$ & $7,7 \mathrm{ab}$ & $7,0 \mathrm{bc}$ & $7,9 \mathrm{a}$ & $5,9 \mathrm{~d}$ \\
Impressão global & $5,9 \mathrm{c}$ & $7,7 \mathrm{a}$ & $6,9 \mathrm{~b}$ & $7,9 \mathrm{a}$ & $6,5 \mathrm{bc}$ \\
\hline
\end{tabular}

A - carne bovina; B, C e D - proteína vegetal. Médias seguidas de mesma letra, em cada linha, não diferem entre si, ao nível de erro de $5 \%$, pelo teste de Tukey.

O hambúrguer de caju apresentou aceitação sensorial inferior à do hambúrguer de carne (amostra A) e a de um dos produtos comerciais à base de proteína vegetal (amostra C), para todos atributos avaliados. Esses produtos comerciais são os que mais se diferenciaram do hambúrguer de caju, apresentando maiores teores de proteína e gordura, o que provavelmente fez com que suas características sensoriais fossem diferentes e sua aceitação maior.

No entanto, a aceitação do hambúrguer de caju não se diferenciou da amostra $\mathrm{D}$ e apresentou avaliações para aparência e textura semelhantes às da amostra $B$, que são justamente as amostras comerciais que apresentaram menores teores de gordura, o que, em geral, está relacionado com produtos menos suculentos, afetando a aceitação sensorial.

Esses resultados permitem observar a grande variabilidade dos produtos disponíveis no mercado e que hambúrgueres vegetais podem apresentar alta aceitação, desde que a formulação seja adequadamente estudada. Apesar das diferenças de aceitação observadas, as avaliações sensoriais para o hambúrguer de caju ficaram próximas à nota 6,0 (gostei ligeiramente) e dentro da faixa de aceitação.

Siqueira et al. (2002) avaliaram a substituição parcial de carne bovina por bagaço de caju na elaboração de hambúrgueres. Os resultados mostraram que o aumento da porcentagem de bagaço de caju estava negativamente correlacionado com a aceitação, porém a adição de até 10\% de bagaço não causou mudanças sensoriais significativas no produto. No entanto, o objetivo desses autores era incorporar bagaço de caju ao hambúrguer de carne e não formular um novo produto apenas à base de caju.

\section{CONCLUSÃO}

Os hambúrgueres elaborados à base de caju apresentaram, em média, menor $\mathrm{pH}$ e menores teores de proteína e gordura do que os produtos comerciais, à base de proteína animal e de proteína vegetal avaliados, sendo a aceitação sensorial correspondente a avaliação gostei ligeiramente.

A elaboração de novas formulações, com a utilização de outros temperos e a associação do caju com proteína de soja, pode melhorar as características nutricionais e sensoriais do produto.

Considerando-se que os preços de hambúrgueres vegetais encontrados no mercado são de 2,5 a 3,5 vezes superiores aos dos hambúrgueres de carne tradicionais, a elaboração de produtos à base de caju é uma alternativa promissora.

\section{AGRADECIMENTOS}

Ao Serviço Nacional de Aprendizagem Rural, administração regional do Ceará, à prefeitura do Município de Beberibe e ao Sindicato Rural de Beberibe, pelo apoio financeiro ao desenvolvimento desse trabalho.

\section{REFERÊNCIAS BILIOGRÁFICAS}

CECCHI, H. M. Fundamentos teóricos e práticos em análise de alimentos. Campinas: Unicamp, 1999. 212 p.

CIONE. Nova culinária nordestina. Fortaleza: [s.n.], [198-]. 56 p.

EMPRESA BRASILEIRA DE PESQUISA AGROPECUÁRIA. Culinária-caju. Disponível em: <http:/ /www.ceinfo.cnpat.embrapa.br>. Acesso em: 30 jan. 2007.

INSTITUTO ADOLFO LUTZ. Normas analíticas do Instituto Adolfo Lutz: métodos químicos e físicos para análises de alimentos. 3. ed. São Paulo, 1985. v. 1, 533 p.

LEITE, L. A. S. A agroindústria do caju no Brasil: políticas públicas e transformações econômicas. 1994. 176 f. Tese (Doutorado em Economia) - Universidade Estadual de Campinas, Campinas, 1994. 
LIMA, L. M. O.; MAGALHÃES, M. M. A.; MEDEIROS, M. F. D.; ALSINA, O. L. S. Utilização de fibras obtidas do bagaço de frutas tropicais no enriquecimento de biscoitos regionais. In: CONGRESSO BRASILEIRO DE CIÊNCIA E TECNOLOGIA DE ALIMENTOS, 18., 2002, Porto Alegre. Anais... Porto Alegre: Sociedade Brasileira de Ciência e Tecnologia de Alimentos, 2002. CD-ROM.

MACFIE, H. J.; BRATCHELL, N.; GREENHFF, K.; VALLIS, L. V. Designs to balance the effect of order of presentation and first-order carry-over effects in hall tests. Journal of Sensory Studies, [S.1.], n. 4, p. 129-148, 1989.

MATIAS, M. F. O.; OLIVEIRA, E. L.; GERTRUDES, E.; MAGALHÃES, M. M. A. Use of fibres obtained from cashew (Anacardium ocidentale, $\mathrm{L}$ ) and guava (Psidium guayava) fruits for enrichment of food products. Brazilian Archives of Biology and Technology, Curitiba, v. 48, p. 143-150, 2005. Edição especial.

MEILGAARD, M.; CIVILLE, G. V.; CARR, B. T. Sensory evaluation techniques. Florida: CRC, 1987. v. 2, 158 p.

PAIVA, F. F. A.; GARRUTTI, D. S.; SILVA NETO, R. M. Aproveitamento industrial do caju. Fortaleza: Embrapa, 2000. 85 p.

PAULA-PESSOA, P. F. A.; LEITE, L. A. S.; PIMENTEL, C. R. M. Situação atual e perspectivas da agroindústria do caju. In: ARAÚJO, J. P. P.; SILVA, V. V. Cajucultura: modernas técnicas de produção. Fortaleza: EmbrapaCNPAT, 1995. p. 23-42.

SIQUEIRA, S. P.; RETONDO, J. C.; MARCELLINI, P. S.; FARIA, J. F. Substituição parcial da carne bovina por bagaço de caju na elaboração de hamburgeres. In: CONGRESSO BRASILEIRO DE CIÊNCIA E TECNOLOGIA DE ALIMENTOS, 18., 2002, Porto Alegre. Anais... Porto Alegre: Sociedade Brasileira de Ciência e Tecnologia de Alimentos, 2002. CD-ROM.

VORTAL DO CAJU. Receitas de caju. Disponível em: <http://www.prossiga.br/caju/>. Acesso em: 30 jan. 2007. 